\title{
The Use of Electronic Health Records in the Exam Room and Patient Satisfaction: A Systematic Review
}

\author{
Jihad S. Irani, MD, MPH, Jennifer L. Middleton, MD, MPH, Ruta Marfatia, MD, \\ Evelyn T. Omana, MD, and Frank D'Amico, PhD
}

Background: Physicians may hesitate to implement electronic health record (EHR) systems because they fear a decrease in patient satisfaction. We conducted a systematic review to determine whether physician EHR use in the patient room affects patient satisfaction.

Methods: We searched the literature using MEDLINE (Ovid), EMBASE, CINAHL, Cochrane Library, PsycINF0, Proceedings First, and ProQuest Digital Dissertations. Our inclusion criteria were a description of physician EHR use in the examination room, EHR use in an outpatient setting, setting in the United States, publication year no earlier than 2000, and measurement of patient satisfaction. We included both qualitative and quantitative research. We included 7 articles in the final analysis: 3 crosssectional, and 4 pre-design and post-design.

Results: Several studies had methodological concerns. Six studies found that physician EHR use had either a positive or neutral effect on patient satisfaction. One study found a negative effect on the physicians' perception of patient satisfaction. The reported statistical results from these studies were not homogenous enough for meta-analysis.

Conclusion: Studies examining physician EHR use have found mostly neutral or positive effects on patient satisfaction, but primary care researchers need to conduct further research for a more definitive answer. (J Am Board Fam Med 2009;22:553-562.)

Electronic health record (EHR) systems are becoming a major component of the twenty-first century health care delivery system, and their adoption by physicians is rising. ${ }^{1}$ Many practitioners hope that electronic medical records will provide more efficient care and reduce medical errors. ${ }^{2}$ Computerbased documentation tools can certainly improve

This article was externally peer reviewed.

Submitted 18 December 2008; revised 10 March 2009; accepted 23 March 2009.

From the Faculty of Health Sciences and the Faculty of Medicine and Medical Sciences, University of Balamand, Beirut, Lebanon (JSI); the University of Pittsburgh Medical Center, St. Margaret, Family Medicine Residency Program and Bloomfield-Garfield Family Health Center, Pittsburgh, PA (JLM); the Department of Family Medicine, University of Pittsburgh, PA (RM, FD); and the Estrella Family Medical, Goodyear, AZ (ETO).

Funding: This work was supported in part by Health Resources and Services Administration grant ID55HPO516201-00.

Conflict of interest: none declared.

Corresponding author: Jihad S. Irani, MD, MPH, Youssef Sursok Street, PO Box 166378, Ashrafieh, Beirut 1100-2807, Lebanon (E-mail: jihad.irani@balamand.edu.lb).

\footnotetext{
See Related Commentary on Page 471.
}

access to summaries of patient care encounters ${ }^{3}$ and they may improve compliance with recommended health maintenance guidelines as well. ${ }^{4,5}$ Perhaps equally important, they can also facilitate practicebased research, quality improvement, and the generation of new knowledge. ${ }^{6}$

The Future of Family Medicine report strongly endorses physician use of EHR, likening it to the "central nervous system of the practice." ${ }^{6}$ The US federal government recently announced initiatives to increase the use of computers in routine ambulatory care. ${ }^{7}$ In addition, the United States' leading primary care physician organizations issued the Joint Principles of the Patient-Centered Medical Home (PCMH) in February of 2007, ${ }^{8}$ with endorsement by the American Medical Association in early 2009'; one PCMH principle specifically relates to the use of information technology to improve the quality and efficiency of health care. ${ }^{8}$

The PCMH model also affirms that patients' satisfaction with their physician is an important marker in health care ${ }^{8,10}$; patient compliance, ${ }^{11-13}$ health outcomes, ${ }^{14-17}$ perceptions of physician competence, ${ }^{18-20}$ and even the incidence of malpractice suits $^{21,22}$ are all closely related to physicians' interpersonal skills. As physicians spend 
more time interacting with the computer, though, some worry that they may have less time to interact effectively with their patients. ${ }^{23}$ Specific fears include a loss of eye contact, less opportunity for psychosocial discussion, and decreased sensitivity to patient responses because of missed nonverbal communication cues. ${ }^{23}$ Researchers have explored the validity of these concerns since the introduction of the ambulatory EHR in the 1970s.

Several studies in the 1980s and 1990s examined the impact on patients of physician computer use in the examination room, including a systematic review that found that both practitioners and patients were concerned about the possible negative impact of computers on the doctor-patient relationship. ${ }^{24}$ Because of refinements and improvements in software design since then, however, these early studies are less applicable to the physicians of today.

More recently, another systematic review in 2004 studied the effect of physician computer use on the quality of care, but it evaluated patient satisfaction only within the context of other studies. ${ }^{25}$ Studies performed in primary care environments during the mid-1990s raised concerns about the potential impact of computer-based documentation on patient satisfaction ${ }^{26}$ and patient-physician communication. ${ }^{4,27}$

No twenty-first century systematic review has yet attempted to provide a definitive answer to these concerns. Our systematic review seeks to examine the impact on patient satisfaction of physician computer use during the ambulatory patient encounter.

\section{Methods}

\section{Study Selection}

We performed an extensive search of the literature from January 2000 until March 2008 using MEDLINE (Ovid), EMBASE, CINAHL, Cochrane Library, PsycINFO, Proceedings First, and ProQuest Digital Dissertations. In addition, we manually searched the citations of the final selection of articles and we used the Web of Science Citation Index to examine articles that cited our selected list. Search strategies were specific to the databases and included Medical Subject Headings associated with keywords that reflected EHRs, patient satisfaction, and the outpatient setting. Two reviewers performed this initial search independently.

We sought to include only studies describing EHR use in the examination room, in an outpatient office setting, published after the year 2000, written in English, performed in the United States, and specifically measuring patient satisfaction as an outcome. We retrieved all papers that addressed the research question in the first screen, regardless of the study design. We excluded editorials, letters, and conceptual papers.

After the first screen, 2 reviewers independently examined the titles and, if needed, abstracts of the retrieved articles to determine which articles were potentially relevant for our analysis (Figure 1). A third reviewer settled any disagreement between the 2 reviewers as was necessary at each stage of the process.

\section{Evaluation Process}

Previous systematic reviews have used scoring systems to assess the validity of studies selected for review. However, existing scoring systems do not provide adequate breadth and depth of criteria to evaluate the wide scope of study methodologies in our set of studies. Thus we will report individual study characteristics without using a scoring system.

\section{Data Extraction and Pooling}

Two reviewers (ETO and RM) independently extracted relevant data from each article into a structured spreadsheet. Source, setting, EHR system used, study design and characteristics, population, year, and reported results were noted. A third reviewer (JSI) reviewed the extracted data tables and confirmed their accuracy.

Of the 7 articles in this review, 2 (Joos et al, ${ }^{28}$ and Rouf et $\mathrm{al}^{23}$ ) only give post-EHR information and hence could not be considered for any type of meta-analysis comparing patient satisfaction scores of both before and after EHR implementation.

Of the remaining 5 articles, which do give some before and after implementation results, 2 Gadd and Penrod articles $\left(2000^{8}\right.$ and $\left.2001^{29}\right)$ give physician satisfaction results on 5-point Likert scales. In these articles, physicians were either asked to rate the rapport they had with their patients before and after EHR implementation on how they perceived the quality of care.

The other 3 articles (Garrison et $\mathrm{al}^{30}{ }^{30} \mathrm{Hsu}$ et $\mathrm{al},{ }^{2}$ and Johnson et $\mathrm{al}^{31}$ ) give patient satisfaction results in percentage format; that is, what percent rated their overall care as either "excellent" or "very good." Even if all 5 papers reported their results 
First Screen: 2103
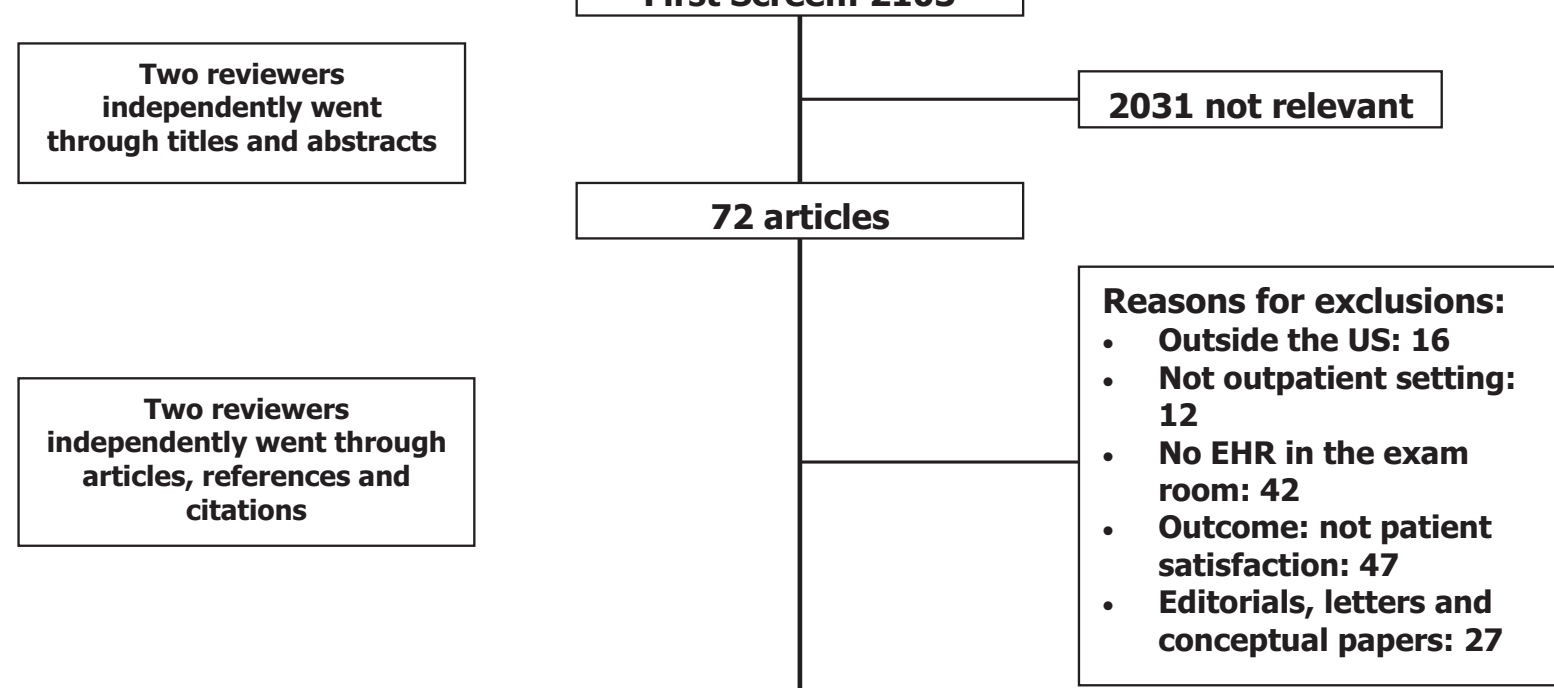

\section{7 articles included: \\ Cross-Sectional: 3 \\ Pre-post: 4}

Figure 1. Study inclusion process. EHR, electronic health record.

using similar statistics (such as all Likert scores), we still think that, because 2 articles sampled physicians and 3 sampled patients, the individuals cited in these articles are too different; therefore, pooling the responses from these articles would not be appropriate.

\section{Results}

Of the original 2103 studies obtained in the first screen, 72 articles' titles and abstracts indicated possible fulfillment of the inclusion criteria; we obtained and reviewed these articles in full.

We excluded the majority of the 72 reviewed articles because of no mention of EHR in the examination room (42 articles) or of patient satisfaction as one of the outcomes ( 47 articles). Two reviewers independently read and judged those 72 articles against our inclusion criteria, resulting in our final list of 7 articles to include in the analysis. Of these 7 articles, 3 were cross-sectional and 4 had a design studying results before and after EHR implementation. No qualitative studies met our inclusion criteria. Overall, the studies were quite disparate in design, participants, and findings.

\section{Study Designs}

All were single-site studies. Three used commercial EHR systems, 3 used noncommercial systems, 2 of the studies were performed by the same author(s), and one did not describe the type of system used. Three used a cross-sectional design and 4 used a predesign/postdesign (Table 1). Only 2 justified their sample size. Methodological design details of the 7 articles may be found in Table 2 .

\section{Study Participants}

Mean age of the patients ranged from 46 to 71.8 years of age. ${ }^{2,8,23,28-31}$ Age of physicians was less consistently and precisely characterized. Response rates varied widely for both patients and physicians. The proportion of male to female patients also varied widely. Demographic data about physicians was not consistently gathered across the studies (Table 1).

\section{Cross-Sectional Studies' Findings}

The 3 cross-sectional studies that we examined found either neutral (Rouf et $\mathrm{al}^{23}$ and Joos et $\mathrm{al}^{28}$ ) or positive $\left(\mathrm{Gadd}\right.$ and $\left.\mathrm{Penrod}{ }^{8}\right)$ patient attitudes about physician EHR use during the outpatient visit, although these attitudes sometimes varied with the physician's level of experience (Table 3).

Rouf et $\mathrm{al}^{23}$ surveyed 155 adult patients from a Veterans Affairs primary care clinic and explored how physician experience modifies the impact of 


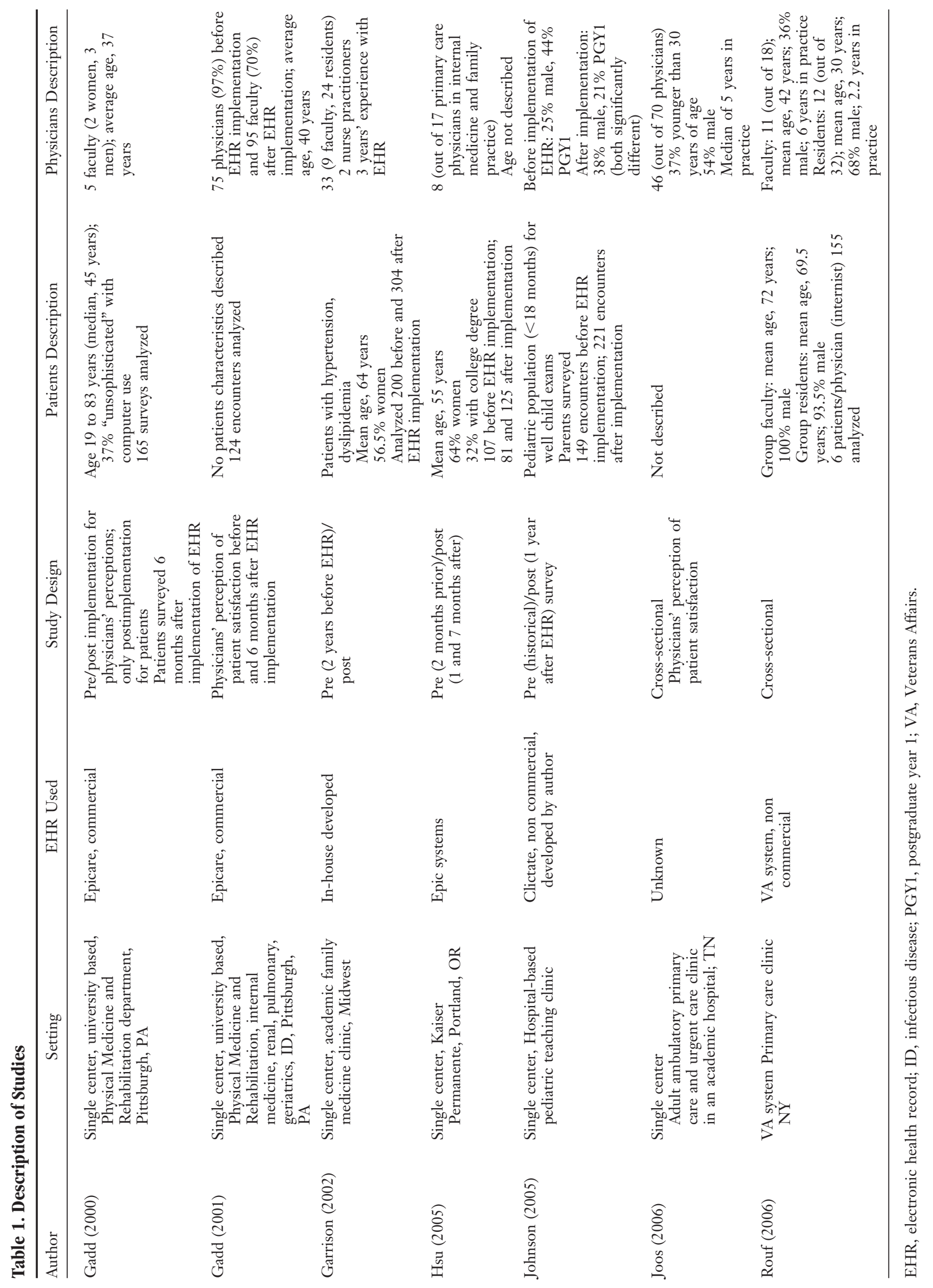

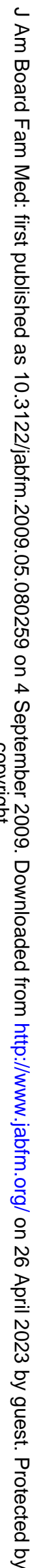




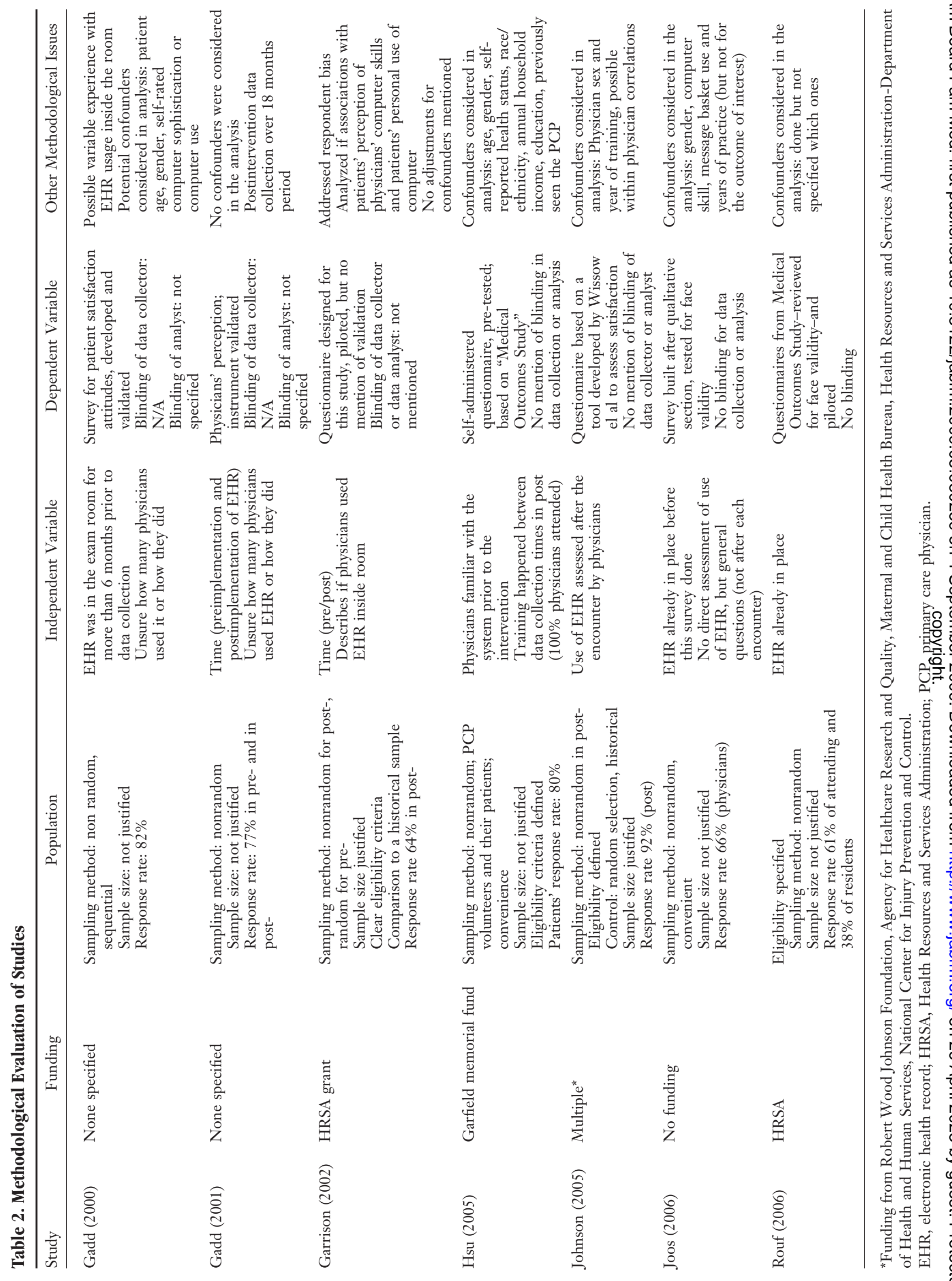




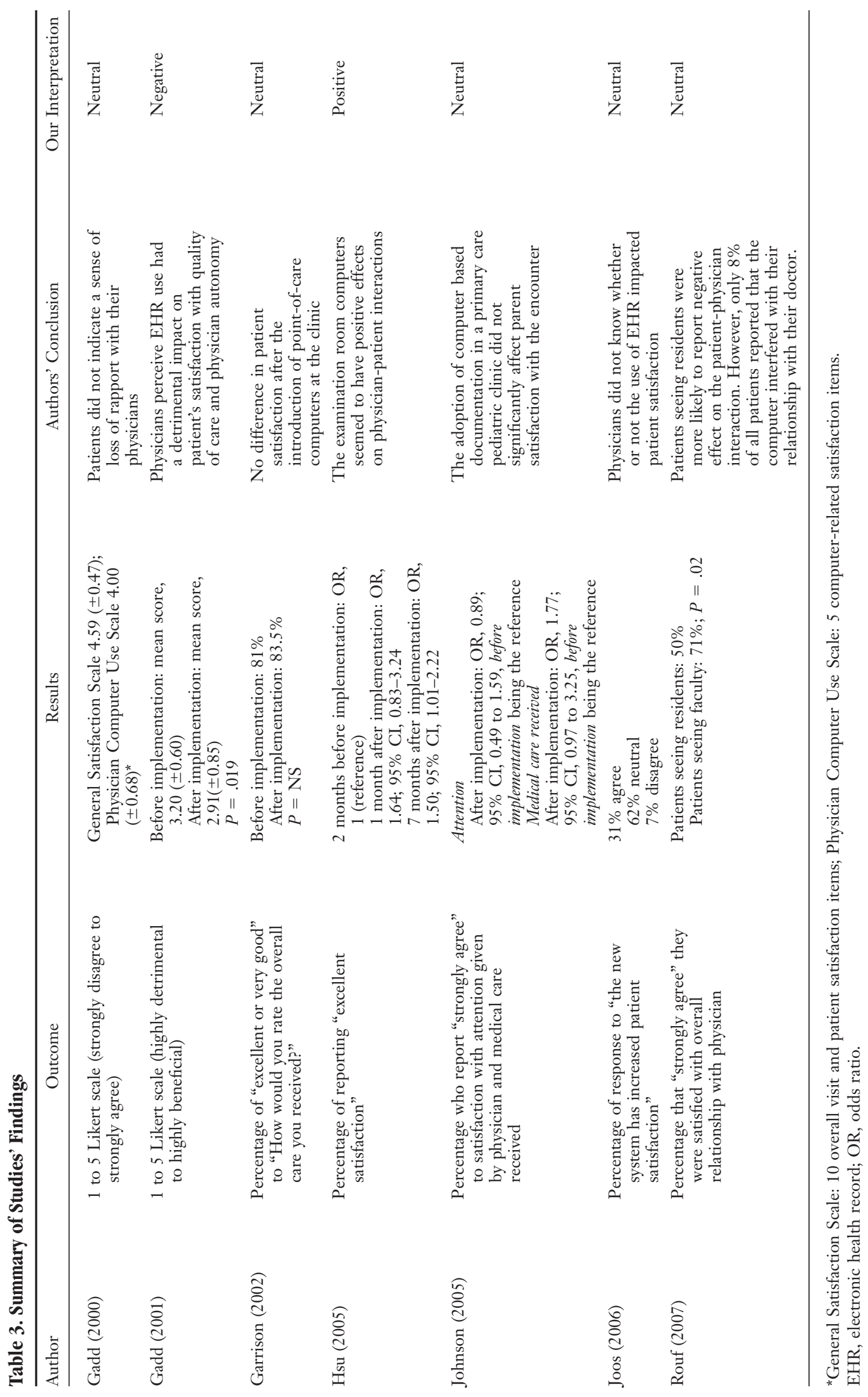


EHR on the physician-patient interaction. This patient population was predominantly white, male, and elderly. The researchers compared responses between those patients seeing residents versus those patients seeing faculty; both resident and faculty used EHRs during the visit. Rouf et $\mathrm{al}^{23}$ used the patient-physician dyad as the unit of analysis and statistically adjusted for the clustering effect of individual patients within physicians. They found that patients seeing trainees were more likely to report potentially negative effects of the computers on their clinical interaction than the patients seeing faculty. Specifically, patients seeing residents were less likely to "strongly agree" that they were satisfied with their overall relationship with the physician than were patients seeing faculty $(50 \%$ vs $71 \%$, respectively; $P=.02$ ). Few patients overall (8\%), however, thought that the computer interfered with the patient-physician relationship.

Joos et $\mathrm{al}^{28}$ also used surveys after EHR implementation to explore its effect on patient satisfaction along with other aspects of clinic process improvement. They only surveyed physicians, so the measures of patient satisfaction were based on physician perception. Of the $66 \%$ of physicians who responded to the survey, $62 \%$ did not think that the EHR had an effect on patient satisfaction whereas $31 \%$ felt that the new system had increased satisfaction and 7\% felt that it had decreased satisfaction.

In 2000, Gadd and Penrod ${ }^{8}$ also found no significant effect on patient satisfaction with physician use of EHR during the encounter. Although this study was a pre/post design, the relevant variables to this review were only measured once (post) and thus we include their results with the other crosssectional studies. They surveyed physicians in Physical Medicine and Rehabilitation outpatient facilities before and after EHR implementation. They also surveyed patients after the implementation regarding "general satisfaction" and "physician computer use." Physicians perceived no effect on patient satisfaction (results cited as "not significant"; numeric results not available) whereas patients reported a high general satisfaction scale (mean score, 4.59 out of 5.00 possible points; SD, $0.47)$.

\section{Pre/Post Studies' Findings}

Two of the 4 studies that evaluated patient satisfaction before and after EHR implementation found no effect on patient satisfaction (ie, neutral results by Johnson et $\mathrm{al}^{31}$ and Garrison et $\mathrm{al}^{30}$ ), whereas one found a positive result $\left(\mathrm{Hsu}\right.$ et $\left.\mathrm{al}^{2}\right)$ and another found a negative effect (Gadd and Pen$\operatorname{rod}^{29}$ ) (Table 3).

Hsu et $\mathrm{al}^{2}$ showed positive findings when assessing patient satisfaction 2 months before and at 1 and 7 months after EHR implementation. ${ }^{2}$ Overall, patients' satisfaction with visits increased 7 months after the introduction of computers (odds ratio [OR], 1.50; 95\% CI, 1.01-2.52) without significant negative effects on other areas such as time available for patient concerns or communication about psychosocial issues.

Johnson et $\mathrm{al}^{31}$ assessed parent and physician satisfaction with ambulatory pediatric visits by comparing preintervention group visits, which used paper-based forms for data entry, versus postintervention visits, which used computer-based documentation. They measured 7 components of the health maintenance encounter, including interim history, social history, anticipatory guidance, developmental assessment, physical examination, assessment, and plan. Results showed no change (ie, a neutral result) in overall parent and physician satisfaction, particularly regarding the attention given by the physician to the patient and family (OR, $0.89 ; 95 \% \mathrm{CI}, 0.49-1.59)$ as well as the overall quality of the medical care received (OR, 1.77; 95\% CI, 0.97-3.25).

Garrison et $\mathrm{al}^{30}$ also found a neutral effect of EHR use on patient satisfaction. They mailed surveys to patients in a family practice office to assess the patients' overall satisfaction with the quality of the health care they received along with their opinions about how their physicians' computer use affected their visit. There were no differences in overall satisfaction between the 1995 survey before adoption of EHR use and the current survey $(P$ reported as "nonsignificant"; specific numerical results are in Table 3 ).

The study by Gadd and Penrod, ${ }^{29}$ published in 2001, tried to determine whether EMR use had any negative impact on patient satisfaction by surveying 6 outpatient practices. Similar to Joos et al, ${ }^{28}$ they used the physician's perception of patient satisfaction as their outcome. The preimplementation survey mean was $3.20(\mathrm{SD}, 0.60)$ and the postimplementation survey mean was 2.91 (SD, 0.85), resulting in a difference of -0.29 (standard error, $0.12 ; P=.019)$. They concluded that physicians 
perceive a decrease in patient satisfaction after EHR implementation.

\section{Meta-Analysis Results}

Of the 7 articles in this review, 2 (Joos et $\mathrm{al}^{28}$ and Rouf et $\mathrm{al}^{23}$ ) only give information after EHR implementation.

A further look into the 2 Gadd and Penrod ${ }^{8,29}$ (2000 and 2001) articles show both slightly favoring satisfaction before implementation of EHR with higher average satisfaction scores than those after EHR implementation (one article was statistically significant).

For the remaining 3 pre/post design articles, all give percentage responses that can be quantitatively pooled. The individual results were for Garrison et $\mathrm{al}^{30}(83.5 \%$ vs $80.5 \%)$, Hsu et $\mathrm{al}^{2}(62.8 \%$ vs $55.3 \%)$, and Johnson et $\mathrm{al}^{31}$ (83.6\% vs $\left.80.5 \%\right)$, all comparing satisfaction after EHR implementation with satisfaction before EHR implementation, respectively. Using random effects modeling for the difference in rates yielded a pooled average difference of $3.7 \%$ ( $95 \%$ bootstrap CI of $2.9 \%$ to $5.2 \%$ ). This finding implies that patients' satisfaction responses may be anywhere from approximately 3 to 5 percentage points higher after the EHR is introduced.

This last section is given for the purposes of being thorough. We caution putting too much emphasis on this interpretation because it represents pooling of only 3 out of 7 articles in our review.

\section{Discussion}

Our goal was to describe patient satisfaction with physician EHR use in a manner that would be highly applicable to current US physicians using, or considering the use of, an EHR system in the ambulatory care setting. Thus, we excluded studies from before 2000, which reviewed systems less commonly in use today. Because the EHR adoption process has been different in Europe, we also excluded papers not in English or studies performed outside of the United States.

Applying these criteria, we found 7 studies that examined patient satisfaction after an ambulatory visit during which the physician used an EHR system in front of the patient. These studies showed mostly a positive or neutral effect of physician EHR use on patient satisfaction, but difficulties inherent in the use of patient satisfaction as an outcome variable are an important limitation to the utility of our findings.

Patient satisfaction as an outcome variable is difficult to precisely measure, ${ }^{32}$ presenting a significant limitation to our study. Many definitions and elements of patient satisfaction exist in the patient satisfaction literature, including patients' expectations as customers, ${ }^{33,34}$ patients' comfort with their physical surroundings, ${ }^{35,36}$ and patients' perceptions of their providers' competence and caring. ${ }^{3,38}$ The disparity of measures that the researchers of our 7 articles used reflect only some of the wide array of patient satisfaction measures available. ${ }^{39}$ In addition, patients tend to rate their physicians favorably, ${ }^{39}$ which can make identifying any change in satisfaction challenging, regardless of metric. ${ }^{40}$

A second limitation to our review was the lack of high-quality randomized control trials coupled with concerns regarding both internal and external validity (Table 2). Examination of our studies' internal validity revealed that only Garrison et $\mathrm{al}^{30}$ and Johnson et $\mathrm{al}^{31}$ justified their sample size. In addition, Gadd and Penrod $^{29}$ and Garrison et $\mathrm{al}^{30}$ did not consider any potential confounders in their analyses. Blinding of analyzers was not described in any of these 7 articles. Some studies (Gadd and Penrod (2000), ${ }^{8}$ Gadd and Penrod (2001), ${ }^{29}$ and Joos et $\mathrm{al}^{28}$ ) did not explicitly measure if the physician used the EHR during the patient encounter. All of these issues-nonjustified sample size, lack of consideration regarding confounders, no direct measure of EHR use-present concerns about the accuracy of the researchers' results in these articles.

Regarding external validity, not one of the 7 included articles randomly selected their patients. At least 2 studies (Hsu et $\mathrm{al}^{2}$ and Joos et $\mathrm{al}^{28}$ ) stated that they used a convenience sample. Although lack of randomization and use of a convenience sample are reasonable methodological choices for these types of study design, they still limit the generalizability of these researchers' findings.

Despite these limitations, these studies still yielded several useful and intriguing findings. For example, patient satisfaction in Johnson et $\mathrm{al}^{31}$ was dependent on physician users' experience with computers and their years in practice. The study by Rouf et $\mathrm{al}^{23}$ similarly stated that patient satisfaction was higher with faculty physicians compared with resident physicians. Both of the Gadd and Pen$\operatorname{rod}^{8,29}$ studies included more precise descriptions 
of physician concerns about EHR implementation: increased time needed to enter orders, increased time needed to provide complete documentation, and effect on rapport between physicians and patients. The mechanisms and biases behind these findings deserve further examination.

Practitioners believe that EHR is good for health care, but the EHR's imprecisely defined effect on patients leads to understandable hesitation by some to implement this beneficial tool. ${ }^{23,29}$ Our systematic review found a mostly positive or neutral effect of physician EHR use on patient satisfaction, but more rigorous studies should be done to more precisely quantify and describe the impact of EHRs on patient satisfaction.

We would like to acknowledge Ahlam Saleh, MD, MLS, reference librarian at the Health Sciences Library System at the University of Pittsburgh; Amy Haugh, MLS, director of the Medical Library Services at University of Pittsburgh Medical Center, St. Margaret; and Karen Zundel, MLS, AHIP, manager of the Health Services Library at University of Pittsburgh Medical Center, McKeesport. We would also like to acknowledge Hajime Kojima, MD, MPH, for his support during the initial phases of the project.

\section{References}

1. Jha AK, Ferris TG, Donelan K, et al. How common are electronic health records in the United States? A summary of the evidence. Health Aff (Millwood) 2006;25:w496-507.

2. Hsu J, Huang J, Fung V, et al. Health information technology and physician-patient interactions: impact of computers on communication during outpatient primary care visits [see comment]. J Am Med Inform Assoc 2005;12:474-80.

3. McDonald CJ, Overhage JM, Tierney WM, et al. The Regenstrief Medical Record System: a quarter century experience. Int J Med Inform 1999;54:22553.

4. Zenni EA, Robinson TN. Effects of structured encounter forms on pediatric house staff knowledge, parent satisfaction, and quality of care. A randomized, controlled trial. Arch Pediatr Adolesc Med 1996;150:975-80.

5. Bell DS, Greenes RA. Evaluation of UltraSTAR: performance of a collaborative structured data entry system. Proc Annu Symp Comput Appl Med Care 1994;216-22.

6. Martin JC, Avant RF, Bowman MA, et al. The Future of Family Medicine: a collaborative project of the family medicine community. Ann Fam Med 2004;2(Suppl 1):S3-32.

7. Bush GW. Executive order 13335 of April 27, 2004: incentives for the use of health information technology and establishing the position of the National
Health Information Technology Coordinator. Federal Register, Vol. 69, No. 84, Presidential documents. Available at: http://edocket.access.gpo.gov/ 2004/pdf/04-10024.pdf. Accessed October 26, 2008.

8. Gadd CS, Penrod LE. Dichotomy between physicians' and patients' attitudes regarding EMR use during outpatient encounters. Proc AMIA Symp 2000:275-9.

9. Bein B. AMA delegates adopt AAFP's joint principles of patient-centered medical home. Ann Fam Med 2009;7:86-7.

10. Dugdale DC, Epstein R, Pantilat SZ. Time and the patient-physician relationship. J Gen Intern Med 1999;14(Suppl 1):S34-40.

11. Schwenk TL, Evans DL, Laden SK, Lewis L. Treatment outcome and physician-patient communication in primary care patients with chronic, recurrent depression. Am J Psychiatry 2004;161:1892-901.

12. Rotenberg KJ, Cunningham J, Hayton N, et al. Development of a Children's Trust in General Physicians Scale. Child Care Health Dev 2008;34:748-56.

13. Moffat M, Cleland J, van der Molen T, Price D. Poor communication may impair optimal asthma care: a qualitative study. Fam Pract 2007;24:65-70.

14. Halbesleben JR, Rathert C. Linking physician burnout and patient outcomes: exploring the dyadic relationship between physicians and patients. Health Care Manage Rev 2008;33:29-39.

15. Kim TW, Samet JH, Cheng DM, Winter MR, Safran DG, Saitz R. Primary care quality and addiction severity: a prospective cohort study. Health Serv Res 2007;42:755-72.

16. Maly RC, Stein JA, Umezawa Y, Leake B, Anglin MD. Racial/ethnic differences in breast cancer outcomes among older patients: effects of physician communication and patient empowerment. Health Psychol 2008;27:728-36.

17. Safran DG, Taira DA, Rogers WH, Kosinski M, Ware JE, Tarlov AR. Linking primary care performance to outcomes of care. J Fam Pract 1998;47: 213-20.

18. Chen JY, Tao ML, Tisnado D, et al. Impact of physician-patient discussions on patient satisfaction. Med Care 2008;46:1157-62.

19. Keating NL, Green DC, Kao AC, Gazmararian JA, Wu VY, Cleary PD. How are patients' specific ambulatory care experiences related to trust, satisfaction, and considering changing physicians? J Gen Intern Med 2002;17:29-39.

20. Waljee JF, Hu ES, Newman LA, Alderman AK. Correlates of patient satisfaction and provider trust after breast-conserving surgery. Cancer 2008;112: 1679-87.

21. Hamasaki T, Takehara T, Hagihara A. Physicians' communication skills with patients and legal liability in decided medical malpractice litigation cases in Japan. BMC Fam Pract 2008;9:43.

22. Stelfox HT, Gandhi TK, Orav EJ, Gustafson ML. 
The relation of patient satisfaction with complaints against physicians and malpractice lawsuits. Am J Med 2005;118:1126-33.

23. Rouf E, Whittle J, Lu N, et al. Computers in the exam room: differences in physician-patient interaction may be due to physician experience. J Gen Intern Med 2007;22:43-8.

24. Mitchell E, Sullivan F. A descriptive feast but an evaluative famine: systematic review of published articles on primary care computing during 1980-97. BMJ 2001;322:279-82.

25. Delpierre C, Cuzin L, Fillaux J, Alvarez M, Massip P, Lang T. A systematic review of computer-based patient record systems and quality of care: more randomized clinical trials or a broader approach? Int J Qual Health Care 2004;16:407-16.

26. Aydin CE, Forsythe DE. Implementing computers in ambulatory care: implications of physician practice patterns for system design. Proc AMIA Symp 1997;677-81.

27. Greatbatch D, Heath C, Campion P, Luff P. How do desk-top computers affect the doctor-patient interaction? Fam Pract 1995;12:32-6.

28. Joos D, Chen Q, Jirjis J, Johnson KB. An electronic medical record in primary care: impact on satisfaction, work efficiency and clinic processes. Proc AMIA Symp 2006;394-8.

29. Gadd CS, Penrod LE. Assessing physician attitudes regarding use of an outpatient EMR: a longitudinal, multi-practice study. Proc AMIA Symp 2001:194-8.

30. Garrison GM, Bernard ME, Rasmussen NH. 21stcentury health care: the effect of computer use by physicians on patient satisfaction at a family medicine clinic. Fam Med 2002;34:362-8.
31. Johnson KB, Serwint JR, Fagan LM, et al. Computerbased documentation: effect on parent and physician satisfaction during a pediatric health maintenance encounter. Arch Pediatr Adolesc Med 2005;159: $250-4$.

32. Fitzpatrick R. Surveys of patients satisfaction: I-Important general considerations. BMJ 1991;302:887-9.

33. Dwore RB. Managing hospital quality performance in two related areas: patient care and customer service. Hosp Top 1993;71:29-34.

34. Omachonu VK. Quality of care and the patient: new criteria for evaluation. Health Care Manage Rev 1990; 15:43-50.

35. Miaoulis G Jr. Say cheese. Photo mapping lets you see your practice as patients do. MGMA Connex 2003;3:42-5, 41.

36. Pangrazio J, Baum N. 10 ways to give your office a face-lift. J Med Pract Manage 2006;21:190-1.

37. Gross R, Brammli-Greenberg S, Tabenkin H, Benbassat J. Primary care physicians' discussion of emotional distress and patient satisfaction. Int J Psychiatry Med 2007;37:331-45.

38. Gross R, Tabenkin H, Brammli-Greenberg S, Benbassat $\mathrm{J}$. The association between inquiry about emotional distress and women's satisfaction with their family physician: findings from a national survey. Women Health 2007;45:51-67.

39. Fitzpatrick R. Surveys of patient satisfaction: II-Designing a questionnaire and conducting a survey. BMJ 1991;302:1129-32.

40. Pascoe GC, Attkisson CC. The evaluation ranking scale: a new methodology for assessing satisfaction. Eval Program Plann 1983;6(3-4):335-47. 